\title{
SURGICAL MANAGEMENT OF SNAKE ENVENOMATION IN CHILDREN
}

\author{
Poovazhagi Varadharajan'1, Suresh Kumar Sankaran², Giridharan V3, Boopathi $K^{4}$, Suresh D5, Monisha A $^{6}$
}

1 Professor, Department of Paediatrics, Chengalpattu Medical College.

${ }^{2}$ Assisstant Professor, Department of Paediatrics, Chengalpattu Medical College.

${ }^{3}$ Professor, Department of Paediatrics Surgery, Chengalpattu Medical College.

${ }^{4}$ Professor, Department of Plastic Surgery, Chengalpattu Medical College.

${ }_{5}^{5}$ Assistant Professor, Department of Paediatrics, Chengalpattu Medical College.

6Junior Resident, Department of Paediatrics, Chengalpattu Medical College.

ABSTRACT

\section{BACKGROUND}

The aim is to study the need for surgical intervention among children with snake envenomation.

\section{MATERIALS AND METHODS}

This was a prospective observational study from a paediatric intensive care unit of a tertiary care institute. Clinical presentation, type of envenomation, need for ASV, duration of hospital stay, surgical intervention and final outcome were studied. Data was analysed using Epi Info software. This study was undertaken after ethical approval and informed consent of caregivers.

\section{RESULTS}

In this study of 35 children, male female ratio was 3.4:1. 71\% were neurotoxic and $69 \%$ had local envenomation. Compartment syndrome was encountered in 13 children (37.14\%). Amputation of the middle finger was undertaken in one child. Initial fasciotomy with subsequent wound debridement was done in 8 children. Split skin grafting was done in 5 children. $36 \%$ of children with neurotoxic envenomation and 54\% with local envenomation and $16 \%$ with haemotoxic envenomation required surgical intervention. Comparison of factors like age, gender, bite to ASV receipt time, number of ASV vials used, initial blood glucose, white blood counts, native treatment did not show any statistically significant difference as risk factors for surgical intervention. Children needing surgical intervention needed a longer hospital stay compared to those who did not need surgical intervention. Except for one child with features of Russell's viper bite others were due to cobra bite in this study group. Overall mortality was 5.7\%.

\section{CONCLUSION}

$36 \%$ of children with snake envenomation from rural areas needed surgical intervention.

\section{KEYWORDS}

Fasciotomy, Snake Envenomation, Split Skin Grafting.

HOW TO CITE THIS ARTICLE: Varadharajan P, Sankaran SK, Giridharan V, et al. Surgical management of snake envenomation in children. J. Evolution Med. Dent. Sci. 2017;6(14):1120-1123, DOI: 10.14260/Jemds/2017/243

\section{BACKGROUND}

Snake envenomation in children is still a major preventable morbidity in rural and semiurban setting. It is a disease of poverty and is a neglected tropical condition. The standard management involves antisnake venom administration and supportive therapy. Surgical intervention and plastic surgical procedures are a need in small number of children with snake envenomation and tissue necrosis. Envenomation following neurotoxic cobra bites and Russell viper bites can lead to tissue necrosis which needs surgical intervention depending on the degree of tissue destruction. Simple incisions for decompression to plastic surgical intervention in multiple sittings may be warranted in some children with extensive tissue necrosis. This study was done to understand the need

Financial or Other, Competing Interest: None.

Submission 29-12-2016, Peer Review 02-02-2017,

Acceptance 08-02-2017, Published 16-02-2017.

Corresponding Author:

Dr. Suresh Kumar Sankaran,

24/10, Old GST Road,

Hanumanthaputheri, Chengalpattu,

Kanchipuram-603002,

Tamilnadu.

E-mail:drsureshich@gmail.com

DOI: $10.14260 /$ jemds $/ 2017 / 243$ of surgical intervention and its outcome among children admitted with snake envenomation at a paediatric tertiary care hospital in a semiurban setting. Majority of the published literature on envenomation in children deals with the clinical presentation, need for ASV, complications and its outcome in children. Scarce publications exist in literature regarding the surgical management of children with tissue necrosis and the outcome. The need for surgical consult and their intervention in snake envenomation though uncommon presents with undue anxiety for the care providers as well as the parents. There is a significant prolongation of hospital stay among children who need surgical intervention. Tissue necrosis is a part of snake envenomation among children with neurotoxic cobra bites and Russell viper bites. Elevation of the limb, incisions to relieve pressure as a decompression procedure in compartment syndrome, surgical debridement, skin grafting, surgical amputation are some of the surgical interventions that are undertaken in children with snake envenomation. Tissue necrosis due to enzymes and other chemical constituents of the venom, infection, unnecessary interventions in the form of tourniquet, native medicine application may contribute to the severity and the need for surgical intervention. 


\section{MATERIAL AND METHODS \\ Type of Study}

Prospective observational study.

Setting: This was done at the paediatric intensive care unit of a semiurban paediatric tertiary care institute, in the government setting. Duration: Jan 2015 to Oct 2016. Study population: All children with features of snake envenomation with or without history of snake bite were recruited for the study. Exclusion criteria: Children who were treated elsewhere whose treatment details were not available as per the data collection proforma were excluded. Sample size: All children with snake envenomation who satisfied the inclusion exclusion criteria during the study period were studied. Children were followed up till discharge or death in case of mortality. Children were recruited for the study after informed consent from the parents or caregivers. Study parameters were detailed history, site of bite, indoor or outdoor bite, type of snake if known, clinical features of signs of neurotoxic, haemotoxic and or local envenomation, bleeding either from the bite site or from any other site, swelling at the site of bite, ptosis, respiratory difficulty, neuroparalysis in the form of weakness of limbs, trunk, head lag, hypotonia, dysphagia, diplopia, drooling of saliva, dysgeusia, altered sensorium, vital signs on admission, pupillary size, pupillary reaction, extraocular movements, hypotonia, absent reflexes, pre-hospital therapy, time interval from bite to hospital admission, time interval from bite to administration of ASV. Indications for ASV administration were presence of signs of neurotoxic envenomation (Ptosis, dysphagia, perioral numbness, diplopia, weakness, paralysis and areflexia), haemotoxic envenomation (Persistent oozing of blood from the bite site, prolonged 20 minute whole blood clotting test) and local envenomation (Swelling crossing a major joint at the bite site or increasing swelling during hospital stay, any swelling that is more than the half the limb bearing the bite site). Compartment syndrome was defined by pallor, pulselessness, pain, colour change with oedema with or without increasing swelling. The need for surgical intervention was decided by the team of paediatric surgeons and the plastic surgeons. The type of surgical intervention in these children were noted along with the duration of hospital stay. Data was analysed using Epi Info statistical software. Study parameters were analysed among the children with and without surgical interventions. Descriptive statistics were used to express the results. Proportions and percentages were obtained. Study was undertaken after institutional ethical approval.

\section{RESULTS}

35 children were recruited for the study based on the inclusion and exclusion criteria. Gender distribution revealed a male female ratio of 3.4:1. (27 males versus 8 females). 16 children were less than 5 years (45.7\%), 16 were between 6 10 years (45.7\%) and 3 were more than 10 years (Fig- 1 ). The site of bite was predominantly in the foot (n-21) followed by hand (n-7), neck (n-1), site not known in 3. Three children did not give history of snake bite. The setting of bite was indoor in 17 (48.6\%), outdoor in 12 (34.3\%) and unknown in $6(17.1 \%)$. The presenting features are summarised in Table 1. Neurotoxic envenomation was encountered in 25 (71.4\%), haemotoxic in $6(17.1 \%)$ and local cellulitis in $24(68.6 \%)$ of them. Of the 35 children, 8 had only neurotoxic features, 2 had only haemotoxic features 7 had only local swelling, 14 had neurotoxicity and local swelling, 1 had haemotoxicity and local swelling, 1 had both haemotoxicity and neurotoxicity and 2 had neurotoxicity, haemotoxicity and local swelling. Comparison of the study parameters among the group with and without surgical intervention was undertaken to identify the risk factors for surgical intervention. 13 children (37\%) required surgical intervention in the study group. Children developed progressive swelling, increasing pain, pricking sensation, feeble pulses, increased pain on passive stretching, discolouration of the limb varying from dusky extremities to bluish discolouration and ulceration (Fig -2). None in the group complained of paraesthesia. Tense painful swelling was the most important clinical finding noted in children with compartment syndrome. None had complete vascular compromise as timely decompression was undertaken. One child got admitted with pregangrenous finger and required amputation. Hand elevation, careful monitoring, pain relievers, broad spectrum antibiotics were given to all children with local swelling. By unit protocol local swelling was managed with Inj. cefotaxime and cloxacillin. Among the 24 children with local swelling, 4 of them did not have progressive increase after admission and 7 of them had progressive swelling but subsided with medical management without evidence of compartment syndrome and 13 required surgical intervention. None of them had compartmental pressure measured; however, digital perfusion was monitored by measurement of saturation by digital pulse oximetry. Among the 25 children with neurotoxic features, 9 required surgical intervention (36\%), among 6 with haemotoxic features one needed surgical intervention (16\%) and among the 24 with local swelling, 13 (54\%) required surgical intervention (Fig -3). Of the study group, one child had Klebsiella and other had Pseudomonas grown in the necrotic samples. Comparison of factors like age, gender, initial blood glucose, bite to ASV receipt time, native treatment, total white blood cell counts, ASV dose required and mean PICU stay did not give significance as risk factors for surgical intervention. (Table 2). However, the mean hospital stay was significantly higher among children who required surgical intervention. Of the 35 children, 2 died (5.7\%) and 33 recovered to hospital discharge.

\begin{tabular}{|c|c|c|c|}
\hline Clinical Feature & N (\%) & Clinical Feature & N (\%) \\
\hline Ptosis & 26 & Abdominal pain & 3 \\
\hline Local swelling & 23 & Diplopia & 2 \\
\hline Voice change & 13 & Local bleeding & 2 \\
\hline Head lag & 13 & Dysphagia & 3 \\
\hline Hypotonia & 10 & Haematemesis & 2 \\
\hline Vomiting & 11 & Epistaxis & 1 \\
\hline Shock at admission & 6 & & \\
\hline \multicolumn{4}{|l}{ Table 1. Clinical Presentation of Envenomation } \\
\hline
\end{tabular}

\begin{tabular}{|c|c|c|c|}
\hline Parameter & $\begin{array}{c}\text { Children with } \\
\text { Surgical } \\
\text { Intervention- mean } \\
\text { (SD) }\end{array}$ & $\begin{array}{c}\text { Children without } \\
\text { Surgical } \\
\text { Intervention } \\
\text { mean (SD) }\end{array}$ & $\begin{array}{c}\text { P- } \\
\text { Value }\end{array}$ \\
\hline Mean age & $\begin{array}{c}5.88 \text { years } \\
( \pm 3.12)\end{array}$ & $\begin{array}{c}6.63 \text { years } \\
( \pm 3.21)\end{array}$ & 0.50 \\
\hline $\begin{array}{c}\text { Bite to ASV } \\
\text { duration }\end{array}$ & $\begin{array}{c}4.41 \mathrm{~h} \\
( \pm 4.8 \mathrm{~h})\end{array}$ & $\begin{array}{c}4.85 \mathrm{~h} \\
( \pm 2.81 \mathrm{~h})\end{array}$ & 0.22 \\
\hline $\begin{array}{c}\text { White blood } \\
\text { cell count }\end{array}$ & $\begin{array}{c}30,261 \\
\text { cells } / \mathrm{cu} . \mathrm{mm}\end{array}$ & $\begin{array}{c}20,731 \mathrm{cells} / \mathrm{cu} . \\
\mathrm{mm}\end{array}$ & 0.511. \\
\hline
\end{tabular}




\begin{tabular}{|c|c|c|c|}
\hline $\begin{array}{c}\text { Initial blood } \\
\text { glucose }\end{array}$ & $\begin{array}{c}149 \mathrm{mg} / \mathrm{dL} \\
( \pm 80.4)\end{array}$ & $\begin{array}{c}181 \mathrm{mg} / \mathrm{dL} \\
( \pm 141.5)\end{array}$ & 0.462 \\
\hline $\begin{array}{c}\text { Mean ASV } \\
\text { vials used }\end{array}$ & $\begin{array}{c}16.15 \text { vials } \\
(5.06)\end{array}$ & $\begin{array}{c}15.45 \text { vials } \\
(5.09)\end{array}$ & 0.69 \\
\hline $\begin{array}{c}\text { PICU stay in } \\
\text { hours }\end{array}$ & $95.23 \pm 42.28$ & $91.4 \pm 69.6$ & 0.528 \\
\hline $\begin{array}{c}\text { Hospital } \\
\text { stay in days }\end{array}$ & $29 \pm 16$ & $4.7 \pm 2.7$ & $0.00^{*}$ \\
\hline
\end{tabular}

Table 2. Showing the Comparison among those with and without Surgical Intervention

* P significant

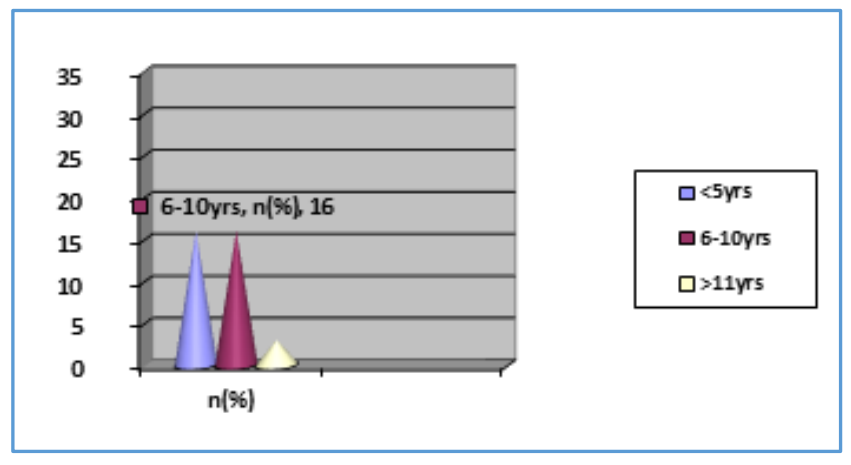

Figure 1. Age Distribution

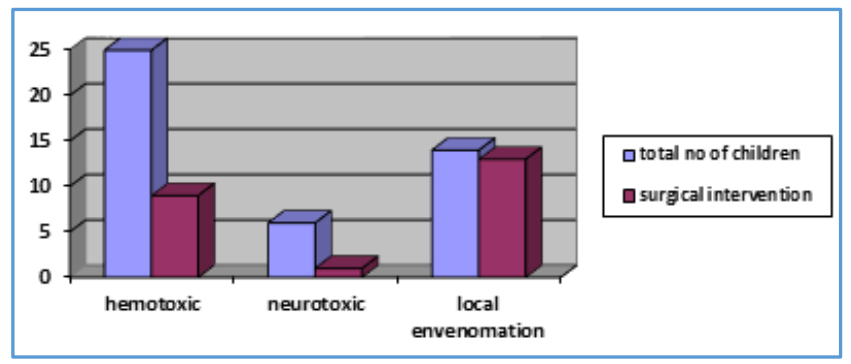

Figure 2. Need for Surgical Intervention

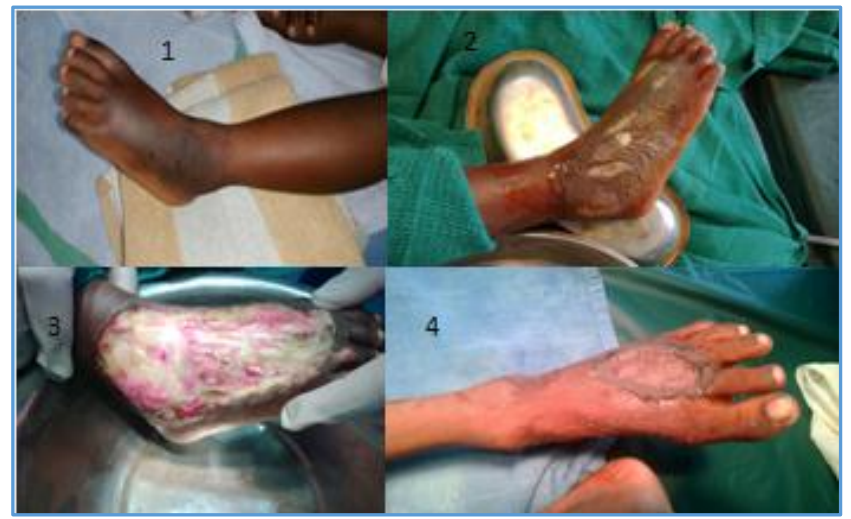

1. Cellulitis. 2-Fasciotomy. 3-Debridement. 4-Skin graft.

Figure 3. Cellulitis and Various Surgical Therapy

\section{DISCUSSION}

Mortality in children with snake envenomation is varied with existing literature. The reported mortality varies from $1.8 \%$ to $13.3 \%$. Our data has shown the mortality as $5.7 \%$. The size of population in this study was not adequate for risk factor analysis of death in snake envenomation. However, delayed presentation could be a contributing factor for this reported mortality. Globally, between 1.2 million and 5.5 million snakebites occur annually leading to as high as $1,84,1000$ envenomings and 94,000 deaths.(1) Snake envenomation in children is a neglected tropical condition. In comparison to adults where the bite is predominantly accidental and outdoors, in children the bite is predominantly indoors. Majority of the time there is not much tissue necrosis in krait bites. However, Russell's viper and cobra are commonly associated with tissue necrosis and this may rapidly progress to vascular compromise and loss of the limb. In this series of cases majority of the bites were neurotoxic (71\%) compared to the published data from elsewhere, documenting haemotoxic bites to be common in children.(2) Local tissue necrosis may result in psychological problems despite survival. Surgical intervention could be incision or excision of the bite site, fasciotomy, and digit dermotomy.(3) Cobra bites were associated with soft tissue necrosis in comparison to viper bites $47.6 \%$ versus $3.6 \%$ respectively.(4) Higher occurrence of local reactions (68\%) in this study population with envenomation could be the reason for higher requirement of surgical intervention. Morganella morganii was identified as the most common organism in those cases.(4) However, in south east Asian regions Staph aureus and Escherichia coli, were the common organisms identified in snake bite wound infections. This study had shown Klebsiella and Pseudomonas were the organisms grown. Monomicrobial was more common than polymicrobial.(5) The same was shown in our study too. In the study by Rha et al, among the 58 children, 13 children (22\%) required surgical intervention in the form of serial wound debridement, followed by skin grafting.(4) Our study has shown that a higher percentage - 37\% (13 of the 35 ) of children required surgical intervention. Tissue necrosis is due to destruction by venom enzymes or distal ischaemia-related compartmental syndrome especially in viper bites. Oedema by the tissue necrosis, might prevent vascularisation of the extremities. This may lead to compartment syndrome. Factors like haemorrhagins, local tourniquet and anaemia due to bleeding may contribute to worsening of compartment syndrome. It is difficult to decide on the need of fasciotomy by any single criteria. Surgical intervention is based on multidisciplinary approach not a single clinical criterion.(6) One study from Korea states that conservative approach would be the best in children with viper bites. Earlier surgical intervention in children with tissue necrosis did not yield good results and had a poor surgical outcome.(7) Surgical intervention is not the first line management of tissue necrosis in snake envenomation.(8) Though intracompartmental pressure was advocated to assess the need for surgical intervention it is rarely ever used in developing countries. Pulseless with tense, swollen, cold limbs might suggest intracompartmental syndrome. More so if the anterior tibial compartment or the digital pulp spaces are involved. Envenomed muscle within such tight fascial compartments results in ischaemia. Clinical signs of compartment syndrome may be difficult to identify in snake bite victims. No surgical intervention should be undertaken until haemostatic abnormalities are corrected.(9) Otherwise the patient may bleed to death. Earlier fasciotomy worsens the myonecrosis in children with envenomation. ${ }^{(10)}$ Role of early fasciotomy is not well documented in literature. $(4,8,11)$ However, early fasciotomy help in enormous pain reduction in the absence of coagulopathy. Children may need multiple surgical debridement procedures in snake envenomation. As most of the snakes harbour aerobic and 
anaerobic organisms in their mouth, antibiotic cover using penicillin and a broad spectrum antibiotic is suggested in management of the local bite site in children with envenomation. Prophylactic use of antibiotic may be justified in developing countries to prevent secondary infection.(12) Compartment syndrome has been encountered in various studies published in literature. It is a rare complication which if untreated leads of loss of function and amputation of the limb. 13,14$)$ Delayed admission to the hospital was found to be a significant factor for compartment syndrome. Literature shows that $28 \%$ had required fasciotomy among a study population of 90 subjects with snake envenomation.(15) Swelling of envenomed muscle within such tight fascial compartments could result in an increase in tissue pressure above the venous pressure and result in ischaemia. However, the classical signs of an intracompartmental pressure syndrome may be difficult to assess in snakebite victims. This study has not identified any risk factors for the need of surgical intervention. Children with surgical intervention had significantly higher days of hospital stay when compared to children who did not require surgical intervention. However, in a rural setting like ours more than $50 \%$ of children with local swelling and more than one third of children with neurotoxic features need surgical intervention. This leads to the question of what are the indications for fasciotomy among children with snake envenomation. Studies have not addressed these issues of recent. However, the bites in the hands, depth of the fang marks, severity of envenomation may be considered as risk factors.(16) Based on studies from adults, fasciotomy should be considered when clinically significant compartment pressures (>30 $\mathrm{mmHg}$ ) are present despite all supportive measures and adequate anti-snake venom therapy. Since most of the centres are not equipped to measure the intracompartment pressure decision is based on the presence of clinical features especially pain out of proportion to the swelling.(17) Based on the existing evidence the need for surgical intervention is still decided by clinical findings on a case to case basis in developing countries. Timely surgical intervention is life \& limb saving in soft tissue necrosis following snake bites.

\section{CONCLUSION}

- Among children with snake envenomation, 71\% were neurotoxic, $69 \%$ had local envenomation and $17 \%$ had haemotoxic envenomation.

- $36 \%$ of children with neurotoxic envenomation, $54 \%$ with local envenomation and $16 \%$ with haemotoxic envenomation required surgical intervention. Overall $36 \%$ of children with snake envenomation in rural areas require surgical intervention.

- Progressive pain, swelling and discolouration are the clues for earlier surgical intervention in children with snake envenomation. Fasciotomy, wound debridement and skin graft were the interventions.

- Comparison of factors like age, gender, bite to ASV receipt time, number of ASV vials used, initial blood glucose, white blood counts, native treatment did not show any statistically significant difference as risk factors for surgical intervention.
- Prolonged hospitalisation was required in children who underwent surgical intervention for snake envenomation.

\section{REFERENCES}

[1] Das RR, Sankar J, Dev N. High-dose versus low-dose antivenom in the treatment of poisonous Snakebites: a systematic review. Indian J Crit Care Med 2015;19(6):340-9.

[2] Kumaravel KS, Ganesh J. A study on the clinical profile of children with Snake envenomation in a tertiary referral centre at Dharmapuri, Tamilnadu, India. Int J Res Med Sci 2016;4(6):2142-5.

[3] Hall EL. Role of surgical intervention in the management of crotaline Snake envenomation. Ann Emerg Med 2001;37(2):175-80.

[4] Laohawiriyakamol S, Sangkhathat S, Chiengkriwate P, et al. Surgery in management of Snake envenomation in children. World J Pediatr 2011;7(4):361-4.

[5] Garg A, Sujatha S, Garg J, et al. Wound infections secondary to Snakebite. J Infect Dev Ctries 2009;3(3):221-3.

[6] Gras S, Plantefève G, Baud F, et al. Snakebite on the hand: lessons from two clinical cases illustrating difficulties of surgical indication. J Venom Anim Toxins including Trop Dis 2012;18(4):467-7.

[7] Lee BJ, Hong SI, Kim HS, et al. Hematological features of coagulopathy and the efficacy of antivenin therapy for a Korean Snakebite. J Korean Surg Soc 2007;72(1):18-26.

[8] Chippaux JP. Surgery should not be used as first line treatment. J Venom Anim Toxins incl Trop Dis 2010;16(1):3-4.

[9] Ahmed SM, Ahmed M, Nadeem A, et al. Emergency treatment of a Snakebite: Pearls from literature. J Emerg Trauma Shock 2008;1(2):97-105.

[10] Tanen DA, Danish DC, Grice GA, et al. Fasciotomy worsens the amount of myonecrosis in a porcine model of crotaline envenomation. Ann Emerg Med 2004;44(2):99-104.

[11] Chattopadhyay A, Patra RD, Shenoy V, et al. Surgical implications of Snakebites. Indian J Pediatr 2004;71(5):397-9.

[12] Palappallil DS. Pattern of use of antibiotics following Snakebite in a tertiary care hospital. Journal of Clinical and Diagnostic Research 2015;9(8):0C05-0C09.

[13] Chew KS, Khor HW, Ahmad R, et al. A five-year retrospective review of Snakebite patients admitted to a tertiary university hospital in Malaysia. Int J Emerg Med 2011;4:41.

[14] Ahmed SM, Nadeem A, Islam MS, et al. Retrospective analysis of Snake victims in Northern India admitted in a tertiary level institute. J Anaesthesiol Clin Pharmacol 2012;28(1):45-50.

[15] Aktar F, Aktar S, Yolbas I, et al. Evaluation of risk factors and follow-up criteria for severity of Snakebite in children. Iran J Pediatr 2016;26(4):e5212.

[16] Ribeiro LA, Jorge MT, Lebrão ML. Prognostic factors for local necrosis in Bothrops jararaca (Brazilian pit viper) bites. Trans R Soc Trop Med Hyg 2001;95(6):630-4.

[17] Dhar D. Compartment syndrome following Snakebite. Oman Medical Journal 2015;13:146. 